\title{
L2 Motivational Self System and L2 achievement: A study of Indonesian EAP learners
}

\author{
Adaninggar Septi Subekti \\ English Education Department, Duta Wacana Christian University, Yogyakarta, Indonesia
}

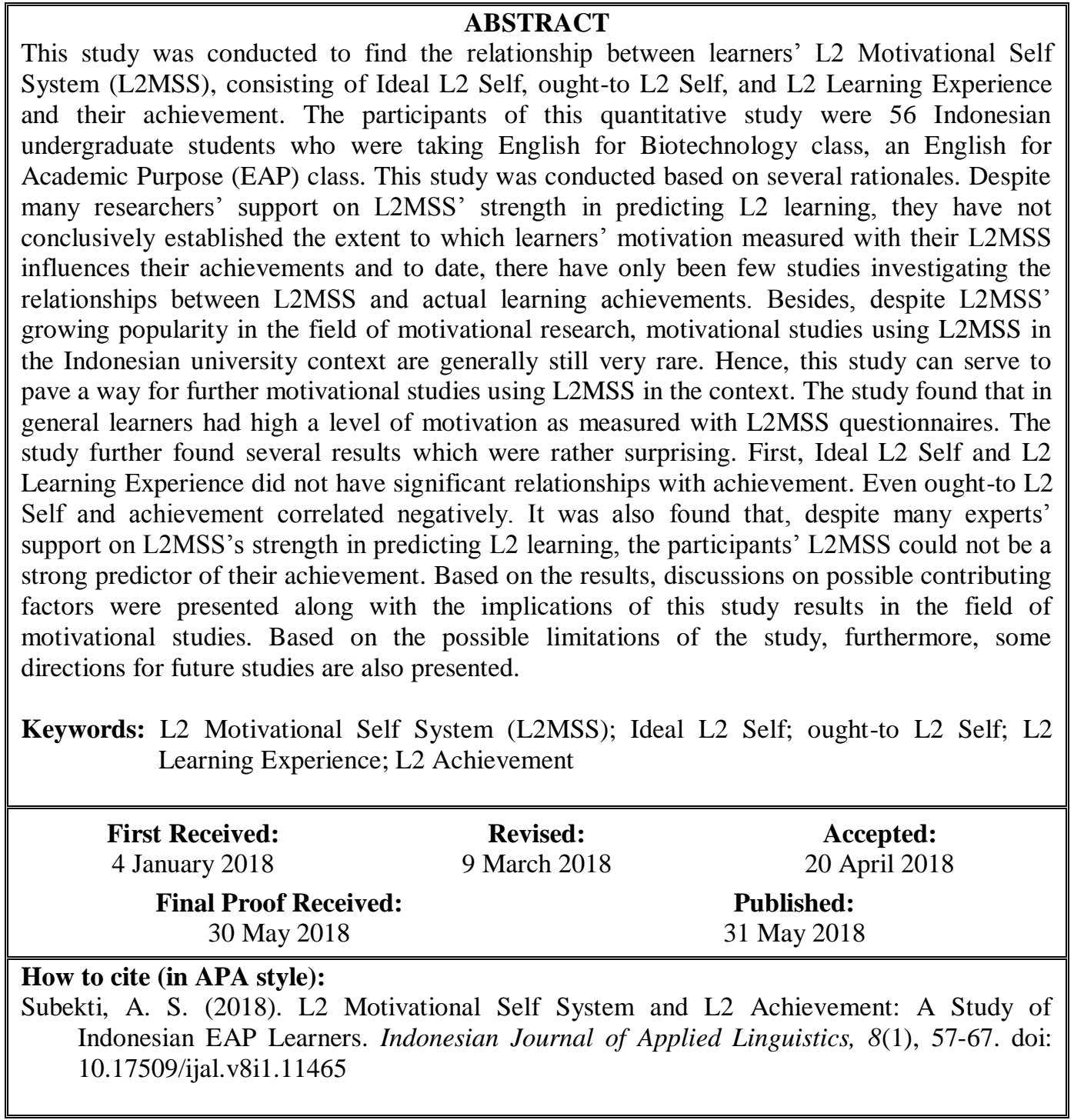

\section{INTRODUCTION}

The importance of learners' individual differences (IDs) has caught interest in second language (L2) studies since the 1960s as it has been observed that there are variations in ultimate success and achievements in L2 learning among learners (Dornyei, 2005). Among other IDs such as language aptitude, learning strategies, and learning styles, furthermore, motivation becomes one of the major ones (Cohen \& Dornyei, 2002; Dornyei, 2005). Therefore, motivation has become an important issue in studies on second language learning.

The word "motivation" itself derives from the Latin verb "movere", which means "to move" (Dornyei \& Ushioda, 2011). It is "what moves a person to make 
certain choices, to engage in action, to expend effort and persist in action" (Dornyei \& Ushioda, 2011, p. 3). Hence, drawing the etymological definition into L2 learning context, Dornyei (2005) and Ortega (2009) argued that motivation nurtures more successful language learning. Dornyei (2005) further stated that motivation gives the primary impetus to begin L2 learning and it then becomes "the driving force to sustain the long and often tedious learning process" (Dornyei, 2005, p. 65). In line with that, Sternberg (2002), an expert in language aptitude, stated that motivation plays a vital role in sustaining learners to keep learning, at times, despite their possible deficiencies in aptitude. Without sufficient motivation, Dornyei (2005) emphasised, even learners of abilities cannot accomplish long-term goals and neither good teaching nor curricula enough on their own can ensure their success. Due to the acknowledgement of the importance of motivation in language learning, furthermore, many studies have been investigating this field.

\section{Early studies on motivation}

Studies on motivation were initiated by the seminal works of Gardner and his students in Canadian context (see Gardner \& Lambert, 1959, 1972) which started what motivational researchers call as the social psychological period (1959-1990). During this period, it was argued that language learning was affected by various sociocultural factors such as language attitudes, cultural familiarity, and stereotypes (Gardner \& Lambert, 1972). This view gave rise to the prominent notions of integrative and instrumental orientations as the antecedents of motivation. Even though Gardner did mention other orientations in his subsequent works (see Gardner, 1985; Tremblay \& Gardner, 1995), he seemed to emphasise the two aforementioned orientations over the others in a model called Socio-Educational Model consisting of three elements, which are, effort, desire, and positive attitude (Gardner, 1985; Gardner \& MacIntyre, 1993). Integrative orientation is defined as learners' interest in L2 learning triggered with their interest in the L2 culture and community (Gardner \& Lambert, 1972). Having integrative orientation, learners are believed to be encouraged to learn more about the L2 culture and community. Different from the integrative orientation which focuses on learners' desire to learn the target language's community and culture, instrumental orientation is more related to pragmatic benefits. For example, someone studies English to get better job opportunities in the future, to get promoted at work, or to get a higher salary. Gardner (1985) stated that to sustain L2 learning, integrative orientation has a more vital role than the instrumental one.

Since the 1990s, however, motivational studies have inclined to concepts of motivation put forward by Dornyei and associates, a phenomenon attributed to the possible weaknesses on the explanatory power of Gardner's concept and the growing prominence of Global English, at least as far as English learning is concerned. First of all, the notion "integrative" in Gardner's model was originated from the Canadian context in which French, the L2 in his study's context, was widely spoken by Canadian participants as it was the second official language after English. Thus, this notion might lose its relevance when applied to contexts in which the L2 is used as "foreign language" and thus learners have relatively minimal exposure to the language (Dornyei \& Ushioda, 2011). Furthermore, Norton (2000) argued that Gardner's and associates' distinguishing learners into "integratively oriented" and "instrumentally oriented" is problematic in the first place. He argued that it is not possible to categorise learners' orientation in such clear-cut criteria. Interestingly, in at least two of his works, Gardner did use these two notions as a pure dichotomy (see Gardner \& MacIntyre, 1991; Gardner, Masgoret, Tenant, \& Mihic, 2004). Besides, there has been confusion in many motivational studies using Gardner's framework on the concept of orientation and motivation. Whilst Gardner clearly emphasised that orientation refers to the reason of studying an L2 and motivation is the driving force (Gardner \& MacIntyre, 1991; Gardner \& Tremblay, 1994), many studies using Gardner's concepts of integrative and instrumental notions have failed to see the difference between them. Such studies as those of Choubsaz and Choubsaz (2014), Samad, Etemadzadeh, and Far (2012), and Yu and Downing (2012), for examples, did treat orientation and motivation as the same entity, despite the fundamental difference between the two notions. Furthermore, the rise of Global English notion also contributes to the decreasing popularity of Gardner's concepts (Dornyei \& Ushioda, 2011; Kachru \& Nelson, 2006). Jenkins (2006) stated that in Global English perspective, rather than seeing native users of English as the benchmark of "right" or "wrong" for L2 users of English, all varieties of English, native or non-native, are equally accepted as it emphasises on intelligibility and allows learners to use English with their own characteristics such as pronunciations, accents, and diction without comparing them with those of English native users. Hence, the growing prominence of Global English also carries the consequence that the notion "integrative orientation" loses its reference because more and more L2 learners no longer look up to English speaking community in learning English (Dornyei \& Ushioda, 2011; Islam, Lamb, \& Chambers, 2013; Lamb, 2004; Ortega, 2009; Ushioda, 2006). In addition, rather than interested in L1 speakers of English, many English learners nowadays develop a bicultural identity in which they identify themselves as a part of both their local culture and the global community (Lamb, 2004; Yashima, 2002, 2009).

Dornyei's L2 Motivational Self System (L2MSS)

Nowadays, L2 motivational studies have shifted to the socio-dynamic period, fuelled by the work of Dornyei known as L2 Motivational Self System (L2MSS) framework (see Dornyei, 2005, 2009). Dornyei (2009) reconceptualised L2 motivation in the way that can add 
our understanding from what Gardner and associates have stated previously but make them relevant in today's globalised world with the growing prominence of Global English. The substantial difference between Gardner's framework and that of Dornyei is that whilst important identifications in Gardner's motivational framework are with others, the L1 community and culture, in Dornyei's framework, they are with the future version of the self. This model is inspired by Higgins' (1987) Self-Discrepancy Theory, in which if learners see discrepancy between their current, actual state as language learners and their desired, ideal selves, they will be motivated to reduce the discrepancy by either learning a new language or improving their proficiency of a language they have been learning. Markus' and Nurius' (1986) Theory of Possible Selves, which tends to be overlooked in Gardner's SocioEducational Model, is also highlighted in Dornyei's L2MSS in which individuals can "see" the self in a future state. That is their ideas of what they might become, what they want to become, and what they are afraid of becoming (Dornyei \& Ushioda, 2011).

L2MSS, furthermore, consists of three components, namely Ideal L2 Self, ought-to L2 Self, and L2 Learning Experience (see Dornyei, 2005, 2009). The first component, Ideal L2 Self, is our personal vision of what we desire to become as language users. Lamb (2012) stated that this component serves as a motivational power inspiring actions towards a desired future and as the facilitator of self-regulation along the way. Dornyei and Ushioda (2011) asserted that Gardner's notions of integrative and instrumental orientations are incorporated in this component. As this component focuses on promotion or improvements, such as hope and accomplishment, learners who learn L2 in the hope that they can be a part of L2 community (integrative orientation) and those who learn L2 in the hope that they can get pragmatic benefits such as a better salary, job opportunities, and job promotions (promotion-focused instrumental orientation) can be said to have been guided by their Ideal L2 Self (Dornyei \& Ushioda, 2011). The second component of L2MSS, furthermore, is ought-to-L2-Self, which refers to "the attributes that one believes one ought to possess" (Dornyei, 2005, p. 105). It is related to one's perceived responsibilities to avoid negative outcomes. Thus, this component is more extrinsic and less internalised than the previously mentioned component. Preventionfocused instrumental orientation in Gardner's view is incorporated in this component (Dornyei \& Ushioda, 2011). An example of this component in language learners is learners who study hard with a pragmatic purpose of avoiding getting bad scores in an exam or failing their class. The last component, L2 Learning Experience, furthermore, refers to situation-specific motives in relation to immediate learning experiences and environments (Dornyei, 2005). This last component acknowledges the possible effects of teachers, curriculum, classroom processes, classmates, and other factors around learners that can affect their motivation to learn L2 (Lamb, 2012).

Supporting Dornyei's (2005, 2009) model of L2MSS, Ushioda (2011) stated that compared to Gardner's model, Dornyei's model has more capabilities to approximate what individuals are experiencing when they are engaging in goal-oriented behaviours such as language learning. It is attributed to the L2MSS's ability to capture the complexity of individuals' motivation rather than to categorize it in a superficially clear-cut boundary (Ushioda, 2011). Due to the stronger explanatory power of Dornyei's L2MSS in understanding learners' motivation, many recent studies investigate learners' motivation using L2MSS as the theoretical framework in various learning contexts (E.g.: Henry, 2013; Islam et al., 2013; Khany \& Amiri, 2016; Lamb, 2012; MacWhinnie \& Mitchell, 2017; Moskovsky, Racheva, Assulaimani, \& Harkins, 2016; Papi, 2010; Papi \& Temouri, 2013; Rajab, Far, \& Etemadzadeh, 2012; Taguchi, Magid, \& Papi, 2009; Ueki \& Takeuchi, 2012; Yaghoubinejad, Zarrinabadi, \& Ketabi, 2016; You \& Dornyei, 2014; You, Dornyei, \& Csizer, 2015).

\section{Studies on L2MSS}

One of the most prominent studies on L2MSS is that of Taguchi et al. (2009) which investigated L2MSS of learners in three different contexts, Japan, China, and Iran, in a comparative study involving 5,000 participants in total. This study found that L2MSS contributed to intended learning effort whilst at the same time found some cross-cultural differences among the three educational contexts investigated. For example, among the Japanese participants, "attitudes to L2 culture and community" on the Ideal L2 Self was almost twice as large as "instrumentality-promotion" on the same component, whereas the contribution of the two mentioned aspects was roughly the same among Chinese and Iranian participants. This finding implied that learners' motivation is context-specific and influenced by many factors surrounding learners (Dornyei \& Ushioda, 2011; Norton, 2000).

Another study conducted by Papi (2010) investigated Iranian learners' motivation using L2MSS and its contribution to learners' anxiety and intended learning effort. This study found that all of the variables in the L2MSS significantly contributed to learners' learning intentions. It also found that the Ideal L2 Self and the L2 Learning Experience minimised the participants' anxiety whilst Ought-to-L2 Self significantly raised their anxiety level. This result might correspond to Dornyei's and Ushioda's (2011) statement that Ideal L2 Self is related to instrumentalitypromotion such as hope and accomplishment, whilst Ought-to-L2 Self is closely related to "instrumentality prevention" such as worry of negative outcomes, thus triggering learners to be more anxious.

A study investigating the relationship between L2MSS and L2 achievement was conducted by Moskovsky et al. (2016) involving 360 participants in 
Saudi educational context. In this study, it was found that L2MSS components were not consistently associated with achievement, measured using learners' reading and writing tests. They argued that the finding could be an evidence that self-reported motivation does not always have consequences in behaviours. In other words, what the participants reported doing might not correspond to what they actually do.

Specific on Indonesian context, furthermore, Lamb's (2012) study investigated 527 Indonesian Junior High School learners of English aged 13-14 in three different contexts: a metropolitan city, a provincial town, and a rural district. It was found that positive views of L2 Learning Experience were the strongest predictor of both intended learning effort and L2 proficiency in all of the three contexts. In this regard, Lamb (2012) further described that peers or classmates played a positive role in this study's sample. On the other hand, he also found that Ideal L2 Self in this study only marginally influenced participants' achievement. Lamb (2012) further argued that this could be attributed to the possibility that Ideal selves in early adolescence tended to be idealistic and vague and thus it became less likely to stimulate actual learning behaviours.

\section{Rationale of the study}

Numerous studies using L2MSS framework investigate the relationships between learners' L2MSS and other aspects such as intended learning effort (E.g.: Papi, 2010; Rajab et al., 2012), self-report proficiency (E.g.: MacWhinnie \& Mitchell, 2017), as well as anxiety and self-efficacy (E.g.: Ueki \& Takeuchi, 2012), yet, interestingly, there have only been few studies (E.g.: Kim \& Kim, 2011; Moskovsky et al., 2016) investigating the relationships between L2MSS and actual learning achievements. Dornyei's (2009) study in Hungarian context, for example, considered learners' intended learning effort the relevant criterion measure, assuming, not demonstrating, that intended learning effort was related to L2 achievement. Research in psychology, however, found that approximately $30 \%$ of intentions do not match actual actions (see Sheeran, 2002). Thus assuming self-reported learning effort identical to L2 achievement might be misleading. Unfortunately, Dornyei (2009), despite considering intended learning effort predictive measure of learners' L2 proficiency, has not conclusively established the extent to which learners' L2MSS influences learners' achievement. Thus, as Moskovsky et al. (2016) asserted that L2 learning is "about achievement, that is, about attaining an adequate level of proficiency" (p. 3), this study seeks to investigate the capacity of L2MSS to predict L2 achievement.

One of few examples of motivational studies using learners' achievement is Lamb's (2012) study. In his study in the Indonesian Junior High School context, he found that L2 Learning Experience became the strongest predictor of achievement among the other components. In Lamb's (2012) study, however, scores based on which he obtained learners' proficiency level were obtained through a test conducted specifically for the purpose of the study and was not conducted in learners' actual class. Hence, to use learners' cumulative scores obtained during one semester in their actual English class, which will be done in the present study, is considered more desirable as it might better measure learners' actual English proficiency. In addition, despite Lamb (2012) very helpful motivational study in Indonesian context, motivational studies using Dornyei's L2MSS in Indonesian university context are generally still very rare. In addition, the context of the present study, which is English for Biotechnology class, an example of English for Academic Purposes (EAP) class, might offer more insights on Indonesian university students' L2MSS. Furthermore, the study which seeks to analyse the extent to which learners' L2MSS influences their L2 achievement might also be beneficial for teachers in the way that they can help learners more effectively in accordance with the results.

In the light of the aforementioned explanations, this study seeks to answer the following research questions. First, how is English for Biotechnology's students' L2MSS? Second, what are the relationships between each component of their L2MSS and their achievement? And third, to what extent does their L2MSS predict their achievement?

\section{METHODS \\ Research design}

The study used a quantitative method of data collection. As the instrument, it used a set of L2MSS Likert-scale questionnaires consisting of 27 items, in which nine items were associated with Ideal L2 Self, nine others with ought-to L2 Self, and the other nine with L2 Learning Experience. These questionnaire items were mainly adapted from Taguchi et al.'s (2009). Whilst Taguchi et al. (2009) employed six scales ranging from Strongly Disagree (one point) to Strongly Agree (six points), the questionnaire used in this study employed five scales, namely Strongly Agree (five points), Agree (four points), Neither Agree nor Disagree (three points), Disagree (two points), and Strongly Disagree (one point). The adjustment was made considering that Indonesian students might be more familiar with fivescaled questionnaire items rather than that of six-scaled like the original questionnaire developed by Taguchi et al. (2009). As Taguchi et al. (2009) did not explicitly have items on L2 Learning Experience and instead, mix them in various categories surrounding learners like parents, teachers, and classmates, for this category, I adapted Taguchi et al.'s (2009) three items related to learners' situation-specific motives and developed six other items on their immediate experience related to English class, English learning, class activities, classmates, and materials. Before distributed, the English version of the questionnaire was translated to Indonesian, the language the participants were much more proficient with. Back translation to English was conducted to ensure that there was no change in 
meaning during the translation process. The translation to Indonesian was also intended to improve the reliability of the data and to improve the participation rate (Thomas, 2013).

The use of the quantitative method in this study, furthermore, was entitled to the strength of the method. First of all, it was fully realised that learners' motivation is such as complex construct and it is unique from one learner to another (Ortega, 2009; Subekti, 2017) and as such studies on motivation also need to acknowledge the dynamicity of motivation which may fluctuate across time (Ortega, 2009). With that in mind, researchers should admit the limit of what a set of questionnaire distributed at some point in learners' life could "do justice" in motivational studies (Subekti, 2017). However, whilst quantitative studies might not capture the fluctuation and dynamicity of a phenomenon experienced by few participants, which is the strength of qualitative studies (Gray, 2014), quantitative studies can produce data that can be generalised to a wider population (Basit, 2010; Gray, 2014). Considering the scarcity of quantitative study using the L2MSS framework in the Indonesian context, furthermore, it becomes very important to investigate this field using a quantitative method to yield generalisable data and thus to pave a way for further research in the field in the Indonesian context.

\section{Data analysis}

The data which were obtained from the questionnaires were entered to SPSS 16 and processed. The data were in the form of the participants' background information and responses to the questionnaire items. The background information was about gender and age. The participants' responses to the questionnaire items were calculated in the form of points. As briefly mentioned above, the questionnaire had five scales in which Strongly Agree equalled to five points, Agree four points, Neither Agree nor Disagree three points, Disagree two points, and lastly Strongly Disagree one point. To obtain the relationship between learners' scores and their L2MSS, Pearson $(r)$ correlation was used. This formula was done to see the relationship between learners' scores and each of the component of the L2MSS, namely Ideal L2 Self, ought-to L2 Self, and L2 Learning Experience. Finally, to see to what extent the participants' L2MSS could predict their achievement, linear regression formula was used.

\section{The participants and the educational context}

The total participants of the study were 56 Biotechnology students taking English for Biotechnology (EB) class, EB class A and class B, at a university in a major city in Indonesia. Most of them were in their third or fifth semester. At the university, all non-English major students, including these participants, were to take a placement English test at the time of their enrolment at the university to determine their English proficiency level. Based on the results of this placement test, they would be placed in a certain level of non-credited three-level General English (GE) classes before being able to take credited EAP classes such as this EB class in their respective departments. In practice, whilst some students might be exempted from taking GE classes and could directly take EAP classes because of their high level of proficiency, the majority of students were required to take GE classes before taking EAP classes. Thus, the participants of this study might have had various lengths of English exposure in English class at the university as some students might need to pass three, two, or one level of GE, before taking EB, whilst few others might not take any GE class at all previously depending on their placement test's scores.

Specific about EB class, furthermore, it was an EAP class intended to prepare learners to read scientific articles and journals for the preparation of their thesis or later careers. More specifically, as seen in the course syllabus, in this class, students were expected to be able to read English popular articles and an English research article on Biotechnology, and to show their understanding through group presentations, weekly worksheets, weekly reflections, midterm test, and final test. The composite scores of these five scoring components were used in this study.

\section{Some ethical considerations}

On the permission of the teacher, the questionnaires were distributed in the last meeting of the odd semester of 2017, on Tuesday, 5 December (EB class A) and Thursday, 7 December 2017 (EB class B) when the participants had Review Session before their final test in the following week. The timing was made in consideration that learners would have more ample time during Review Session than that of regular sessions before, in which they had compact class activities such as doing presentations and worksheets. It was done to respect the participants' learning time, and to minimise possible disruption (Oliver, 2003; Thomas, 2013). Besides, ample time allows participants to respond to items more carefully and thus contributes to more reliable data (Bryman, 2012; Thomas, 2013).

The students' voluntary participation in this study, furthermore, was ensured through written consent forms (Gray, 2014; Israel \& Hay, 2006). Hence, returned questionnaires would only be further analysed if the attached consent forms, detailing the purpose of the study and the participants' rights, were signed by the students. They were also given the guidelines of no intervention, no coercion, and confidentiality to ensure that they knew their rights as participants (Oliver, 2003) and were willing to respond to the questionnaire items honestly, and thus could maintain the reliability of the data (Bryman, 2012). Students' final scores were given in accordance with the signed returned questionnaires. All data appearing in the report were made anonymous to keep the participants' confidentiality (Israel \& Hay, 2006; Thomas, 2013). 


\section{FINDINGS AND DISCUSSIONS}

From the total of 68 students taking EB in the odd semester of 2017, 57 students participated in the study by filling in the questionnaires and signing the consent forms. Eleven other students were either absent on the days the questionnaires were distributed or did attend the class but decided to not participate. Despite the less number of participants, this also showed that some students did exercise their rights of not participating in the study, thus implying the principles of ethics were maintained (Gray, 2014). One questionnaire was returned incomplete, and thus was excluded from further analysis, leaving 56 completed questionnaires. 46 participants $(82.1 \%)$ indicated their willingness to be invited to interviews in a possible follow-up study, which indicated great enthusiasm of the participants in participating in the study. The minimum age of the participant was 18 , whilst the maximum was 23 . The mean was $19.4(S D=1.31)$. Moreover, of the total of 56 participants, eleven (19\%) were male, whilst 45 were female $(80.4 \%)$.

The L2MSS questionnaire had .89 Cronbach's Alpha coefficient for the nine items of Ideal L2 Self, .84 for the nine items of ought-to L2 Self, and .89 for the nine items of L2 Learning Experience. That the Cronbach's Alpha coefficients of all the three components of L2MSS were close to 1 indicated that the questionnaire items in all the three components had high internal reliability.

In the following sections, results and discussions on each of the research questions will be elaborated further.

\section{Research Question 1: How is English for Biotechnology students' L2MSS?}

Among the three components of L2MSS, learners' Ideal L2 Self ranked the highest $(M=37.62)$, their L2 Learning Experience was in the second $(M=35.75)$, and ought-to L2 Self was in the third position $(M=$ 32.57). Interestingly, the finding that the mean score of ought-to L2 Self was the lowest among the L2MSS components was the same as that of Dornyei's and Chan's (2013) study in China. It indicated that societal and peer expectations only had a moderate influence on the Indonesian learners and on their Chinese counterparts. Keeping in mind that this was the result of a 27-item questionnaire, furthermore, the composite L2MSS's mean score being 105.91 indicated high motivation with the mean score for each questionnaire item being 3.92 out of 5 . Generally, this result indicated that the participants reported that they had a high motivation in relation to their L2 learning. The complete results can be seen in Table 1. Furthermore, the table showing the participants' responses on each of the questionnaire items in the form of percentages can be seen in the Appendix at the end of this report. As could be observed in the appendix, despite various responses the participants gave, in general, their responses tended to fall to the either "Strongly Agree" or "Agree" with much less percentage on either "Disagree" or "Strongly
Disagree". The results, along with the results of the composite mean scores for each component of L2MSS shown in Table 1, indicated that in general, the participants had a high level of motivation. As seen in Table 2, however, the afore-mentioned results should be interpreted with cautions.

Table 1. Descriptive Statistics of Learners' L2MSS

\begin{tabular}{lcc}
\hline \multicolumn{1}{c}{ Components } & Mean & Standard Deviation \\
\hline Ideal L2 Self & 37.62 & 4.69 \\
Ought-to L2 Self & 32.53 & 5.81 \\
L2 Learning Experience & 35.75 & 5.38 \\
Total L2MSS & 105.91 & 11.68 \\
\hline
\end{tabular}

Table 2: The means of the participants' responses

\begin{tabular}{cccccc}
\hline \multicolumn{2}{c}{ Ideal L2 Self } & \multicolumn{2}{c}{$\begin{array}{c}\text { Ought-to L2 } \\
\text { Self }\end{array}$} & \multicolumn{2}{c}{$\begin{array}{c}\text { L2 Learning } \\
\text { Experience }\end{array}$} \\
\hline Items & Mean & Items & Mean & Items & Mean \\
\hline 1 & 4.27 & 10 & 3.96 & 19 & 3.93 \\
2 & 4.16 & 11 & 4.00 & 20 & 4.30 \\
3 & 4.20 & 12 & 4.14 & 21 & 3.45 \\
4 & 4.16 & 13 & 3.91 & 22 & 4.04 \\
5 & 3.62 & 14 & 2.68 & 23 & 3.88 \\
6 & 4.25 & 15 & 3.89 & 24 & 3.80 \\
7 & 4.71 & 16 & 4.04 & 25 & 3.96 \\
8 & 4.11 & 17 & 3.04 & 26 & 4.00 \\
9 & 4.14 & 18 & 2.88 & 27 & 4.39 \\
\hline
\end{tabular}

First, as seen in Table 2, some items yielded mean scores close to 3.00 , which indicated low motivation in relation to the corresponding items. In Ideal L2 Self category, item number five, "I can imagine myself speaking English as if I were a native speaker of English", for example, the mean was only 3.62, the only one with the value below 4.00 in the category. In addition, with the majority of the respondents (39.3\%) neither agreed nor disagreed to the statement, as seen in the appendix, it could be implied that they had difficulty picturing themselves being able to speak the way native users of English do as a possible future self-image.

Moreover, there were three items in the ought-to L2 Self category which yielded even lower mean scores. Item number 14, "Studying English is important to me in order to gain approval of my teachers and peers," had the mean score of 2.68 , with $80.4 \%$ of the participants responding the statement with 1,2 , or 3 . This might indicate that they did not see either teachers' or peers' acknowledgment as a driving force to learn English. Interestingly, this might also indicate that they did not see their teachers and peers as ones that would acknowledge them solely because of their English mastery. Further, this could be closely related to the context of the study or the participants' surroundings, which, whilst possibly acknowledging the importance of English, did not place English mastery in a very superior position. The next was item number 17, "Studying English is important to me because other people will respect me more if I have a knowledge of English" with the mean score of 3.04. Only 32.2\% of the respondents strongly agreed or agreed to the statement. Furthermore, item number 18, "If I fail to 
learn English, I will be letting other people down" only had 2.88 mean score. $30.4 \%$ of the respondents either disagreed or strongly disagreed, whilst only $23.2 \%$ either strongly agreed or agreed with the statement. This item's result might be related to the result of the previously mentioned items number 14 and 17. That was to state that the social context of the participants which had very limited use of English in daily life and thus did not consider English mastery extremely crucial might play a role in the results. The results indicative to the role of social context of the participants confirmed some experts' statement that cultural differences play a vital role in determining learners' L2MSS (Dornyei \& Chan, 2013; Lamb, 2012; Ortega, 2009).

Furthermore, item in L2 Learning Experience category which had the lowest mean score among the others in the category was item number $21(M=3.45)$. Even though $46.4 \%$ of the respondents gave their agreement to the statement, "I always look forward to English classes," $41.1 \%$ of the respondents neither agreed nor disagreed with it. This result might be attributed to activities in EB class which necessitated them to read and understand English popular articles and scientific journal articles in Biotechnology, which some participants might find tedious and not so easy.

\section{Research Question 2: What are the relationships between each component of learners' L2MSS and their achievement?}

The results of the correlation formula between learners' scores and L2MSS components could be observed in Table 3.

Table 3: Correlations between Scores and Components of L2MSS

\begin{tabular}{ccccc}
\hline & Ideal L2 Self & Ought-to L2 Self & L2 Learning Experience \\
\hline Pearson Correlation & .041 & -.105 & .100 \\
Learners' Scores & .762 & .441 & .464 \\
N Sig. (2-tailed) & 56 & 56 & 56 \\
\hline
\end{tabular}

Correlation is significant at the 0.05 level (2-tailed).

From the table above, some findings could be stated. The first, all of the three correlations conducted indicated the relationships between scores and each of the L2MSS components were not statistically significant. Secondly, whilst there were relationships between learners' scores and the components, they were very small. The scores' correlation with Ideal L2 Self was nearly zero, $r(56)=.04, p>.05$, indicating almost no relationship. Its correlation with L2 Learning Experience was higher, despite very small, $r(56)=.10$, $p>.05$. Finally, even though the correlation between scores and ought-to L2 Self was very small as well, $r$ $(56)=-.11, p>.05$, it was interesting that the direction of correlation was negative. It means that the higher ought-to L2 Self was the lower learners' scores tended to be, however small the relationship was. In regard to these results, even though they were rather surprising, they could still be explained.

First, the small correlation between scores and Ideal L2 Self might be attributed to the young participants' vague and too idealistic view of their Ideal L2 Self. Instead of picturing their realistic possible selves in the future, the participants' responses on Ideal L2 Self category might reflect their hope and positive attitude towards their future. These views, however, were possibly not accompanied with sufficient learning effort. Hence, it was unlikely to contribute much to their L2 achievement (Moskovsky et al., 2016). Interestingly, this finding, despite rather surprising, was not totally new. Dornyei's and Chan's (2013) study in Chinese context also found statistically not significant small correlations between English scores and Ideal L2 Self. In addition, Lamb's (2012) study also found that Ideal L2 Self only marginally influenced L2 achievement. Even, Moskovsky et al. (2016) study in Saudi Arabia found a negative relationship. Such results confirmed that "a highly unlikely possible self probably will have little relation to motivation" (MacIntyre, MacKinnon, \& Clement, 2009, p. 197).

Secondly, that L2 Learning Experience had the strongest relationship with achievement among the three components of L2MSS corresponded to the results of Lamb's (2012) study in Sumatra, Indonesia. This might be attributed to the relatively same social and educational context of the participants in both studies. That suggested that their immediate learning experience related to the atmosphere in English class, class activities, English teachers, classmates, and learning materials contributed more to their L2MSS than those of their possible selves, confirming Ortega (2009) idea on the influence of immediate learning environments on learners' motivation.

Finally, with regard to the negative correlation between learners' scores and ought-to L2 Self, some experts had their views. Dornyei and Chan (2013), for example, argued that whilst ought-to L2 Self has a contribution to learners' motivation, it lacks the energizing drive to make a difference in real motivated behaviours in many educational contexts by itself. Moskovsky et al. (2016) study which yielded the same negative result further confirmed this. In regard to this, MacIntyre et al. (2009) stated that cultural differences in learners' self-concepts can affect the motivational qualities of possible selves, including their Ought-to L2 Self. In the participants' cultural and educational context in which English was not used extensively in daily communication, nor was it used as the introductory language at the university, the participants might not see any obligation to avoid negative outcomes such as making people around them disappointed and 
being less acknowledged or respected. That was because the society among whom they lived did not consider English very important and did not use English extensively.

\section{Research Question 3: To what extent does learners' L2MSS predict their achievement? \\ To find the extent to which learners' L2MSS could predict learners' scores, linear regression was performed. As seen in Table 4, the value of $R^{2}$ was .028 . It means that learners' L2MSS could predict $2.8 \%$ of their scores, with other possible variables, which together made up the other $97.2 \%$, not involved in the regression formula. The result could be observed in Table 4 below.}

Table 4: Regression results with learners' scores as dependent variable

\begin{tabular}{cccc}
\hline & $\mathrm{R}$ & $\mathrm{R}$ Square & Adjusted R Square \\
\hline 1 & $.169^{\mathrm{a}}$ & .028 & -.028 \\
\hline
\end{tabular}

a. Predictors: (Constant), L2 Learning Experience, Ought to L2 Self, Ideal L2 Self

Whilst the result indicated that learners' L2MSS could only explain $2.8 \%$ of the variance in their scores, the finding was not totally surprising. Papi (2010) argued that L2 achievement is determined by various factors and asserted that motivation, despite being the driving force of effortful learning behaviours (Dornyei, 2005), is merely indirectly related to L2 achievement. In addition, Moskovsky et al. (2016) also found that "selfreported motivation does not always have behavioural consequences" (p. 4).

To summarise, the present study seeking to investigate the relationship between L2MSS and L2 achievement generally found that the three components of L2MSS were not consistently correlated with learners' achievement. The L2MSS, furthermore, could only predict $2.8 \%$ of learners' achievement. These results, overall, contradicted previous studies suggesting that learners' L2MSS became a strong predictor of their intended learning effort (E.g.: Islam et al., 2013; Papi, 2010; Rajab et al., 2012; Taguchi et al., 2009). It was, however, approximately in line with other studies which found that learners' L2MSS could not be a strong predictor of achievement (E.g.: Kim \& Kim, 2011; Lamb, 2012; Moskovsky et al., 2016). From the results of these various studies, it could be stated that whilst learners' L2MSS could predict their self-reported learning intentions, it could not be a strong predictor of their actual achievement. Finally, the present study results also served as an evidence that a lot more than merely the operation of Dornyei (2009) L2MSS is at play in the motivation-achievement relationship.

\section{CONCLUSION}

\section{Limitations}

This study, despite its possible useful findings on Indonesian learners' L2MSS-achievement relationship, has some limitations. Firstly, the quantitative method of distributing questionnaires, whilst able to reach more participants, could not do justice to investigate learners' actual motivated behaviours. The result, in which the participants' self-reported high motivation could not significantly predict their achievement, could be attributed to the drawback of using a self-reported instrument. Hence, possibly, their reported high motivation was not translated into real motivated learning behaviours. Secondly, whilst the results of the current study could be generalised, it should be viewed within the context of population, Indonesian undergraduate non-English major university students.

\section{Future Studies}

In the light of the results of the present study, some directions of future studies could be suggested. That the current study results indicated that learners' high motivation did not correlate significantly with their achievement could imply that their self-reported high motivation was not accompanied by actual actions. Thus, it becomes important to see the extent to which learners show motivated behaviours. Therefore, conducting mixed-method or qualitative investigations, using observations and interviews, on learners' motivation, rather than solely conducting quantitative investigations, might be worthwhile. Also, considering L2MSS, which could be a strong predictor of selfreported intended learning effort, could not significantly predict L2 achievement, the ultimate goal of learning, it is suggested that the seemingly appealing proposition suggesting that learners' intended learning effort will result in improved proficiency should not be treated axiomatically. That is to say, researchers should focus their attention to investigate the extent to which learners' L2MSS can predict their achievement or actual proficiency rather than their self-report learning intentions as these intentions are not always translated into motivated behaviours (Moskovsky et al., 2016).

\section{REFERENCES}

Basit, T. N. (2010). Conducting research in educational contexts. London: Continuum International Publishing Group.

Bryman, A. (2012). Social research methods ( ${ }^{\text {th }}$ Ed.). Oxford: Oxford University Press.

Choubsaz, Y., \& Choubsaz, Y. (2014). Motivational orientation of EFL learning: A study of Iranian undergraduate students. Procedia-Social and Behavioral Sciences, 98, 392-397.

Cohen, A., \& Dornyei, Z. (2002). Focus on the language learner: Motivation, styles, and strategies. In N. Schmidt (Ed.), An introduction to applied linguistics (pp. 170-190). London: Arnold.

Dornyei, Z. (2005). The psychology of the language learner: Individual differences in second language acquisition. Mahwah, NJ: Lawrence Erlbaum.

Dornyei, Z. (2009). The L2 motivational self system. In Z. Dornyei \& E. Ushioda (Eds.), Motivation, 
language identity, and the L2 self (pp. 9-42).

Bristol, UK: Multilingual Matters.

Dornyei, Z., \& Chan, L. (2013). Motivation and vision: An analysis of future L2 self-images, sensory styles, and imagery capacity across two target languages. Language Learning, 63, 437-446.

Dornyei, Z., \& Ushioda, E. (2011). Teaching and researching motivation (Second Edi). New York: Routledge.

Gardner, R. C. (1985). Social psychology and second language learning: The role of attitudes and motivations. London: Edward Arnold.

Gardner, R. C., \& Lambert, W. (1959). Motivational variables in second language acquisition. Canadian Journal of Psychology, 13, 266-272.

Gardner, R. C., \& Lambert, W. E. (1972). Attitudes and motivation in second language learning. Massachusetts: Newbury House Publishers Inc.

Gardner, R. C., \& MacIntyre, P. D. (1991). An instrumental motivation in language study: Who says it is not effective? SSLA, 13, 57-72.

Gardner, R. C., \& MacIntyre, P. D. (1993). On the measurement of affective variables in second language learning. Language Learning, 43(2), 157-194.

Gardner, R. C., Masgoret, A. M., Tenant, J., \& Mihic, L. (2004). Integrative motivation: Changes during a year-long intermediate-level English course. Language Learning, 54(1), 1-34.

Gardner, R. C., \& Tremblay, P. F. (1994). On motivation, research agendas, and theoretical frameworks. The Modern Language Journal, 78(3), 359-368.

Gray, D. E. (2014). Doing research in the real world ( $3^{\text {rd }}$ Ed.). London: Sage Publications, Ltd.

Henry, A. (2013). The motivational effect of crosslinguistic awareness: Developing third language pedagogies to address the negative impact of the L2 and the L3 self-concept. Innovation in Language Learning and Teaching. https://doi.org/10.1080/175001229.2013.733008

Higgins, E. T. (1987). Self-discrepancy: A theory relating self and affect. Psychological Review, 94(3), 319-340.

Islam, M., Lamb, M., \& Chambers, G. (2013). The L2 motivational self-system and national interest: A Pakistani perspective. System, 41, 231-244.

Israel, M., \& Hay, I. (2006). Research ethics for social scientists. London: Sage Publications.

Jenkins, J. (2006). Points of view and blind spots: ELF and SLA. International Journal of Applied Linguistics, 16(2), 137-162.

Kachru, Y., \& Nelson, C. L. (2006). World Englishes in Asian contexts. Hong Kong: Hong Kong University Press.

Khany, R., \& Amiri, M. (2016). Action control, L2 motivational self-system, and motivated learning behaviour in a foreign language learning context. Instituto Superior de Psicologia Aplicada, Lisboa, Portugal and Springer+Bussiness Media
Dordrecht. https://doi.org/10.1007/s10212-0160325-6

Kim, Y. K., \& Kim, T. Y. (2011). The effect of Korean secondary school students' perceptual learning styles and ideal L2 self on motivated L2 behavior and English proficiency. Korean Journal of English Language and Linguistics, 11, 21-42.

Lamb, M. (2004). Integrative motivation in globalizing world. System, 32, 3-19.

Lamb, M. (2012). A self system perspective of young adolescents' motivation to learn English in urban and rural setting. Language Learning, 997-1023.

MacIntyre, P. D., MacKinnon, S. P., \& Clement, R. (2009). Toward the development of a scale to assess possible selves as a source of language learning motivation. In Z. Dörnyei \& E. Ushioda (Eds.), Motivation, Language Identity, and the L2 Self (pp. 193-214). Bristol, UK: Multilingual Matters.

MacWhinnie, S., \& Mitchell, C. (2017). English classroom reforms in Japan: A study of Japanese university EFL student anxiety and motivation. Asian-Pacific Journal of Second and Foreign Language Education, 2(7), 1-13. https://doi.org/10.1186/s40862-017-0030-2

Markus, H., \& Nurius, P. (1986). Possible selves. American Psychologist, 41, 954-969.

Moskovsky, C., Racheva, S., Assulaimani, T., \& Harkins, J. (2016). The L2 motivational self system and L2 achievement: A study of Saudi EFL learners. The Modern Language Journal, 100, 114.

Norton, B. (2000). Identity and language learning: Gender, ethnicity, and educational change. Harlow: Longman.

Oliver, P. (2003). The student's guide to research ethics. New York: Open University Press.

Ortega, L. (2009). Understanding second language acquisition. New York: Routledge.

Papi, M. (2010). The L2 motivational self system, L2 anxiety, and motivated behavior: a structural equation modeling approach. System, . System, 38, 467-479.

Papi, M., \& Temouri, Y. (2013). Dynamics of self and motivation: A cross-sectional study of the EFL context in Iran. International Journal of Applied Linguistics, 2(3), 288-309.

Rajab, A., Far, H. R., \& Etemadzadeh, A. (2012). The relationship between L2 motivational self-system and L2 learning among TESL students in Iran. Procedia - Social and Behavioural Sciences, 66, 419-424.

Samad, A. A., Etemadzadeh, A., \& Far, H. R. (2012). Motivation and language proficiency: Instrumental and integrative aspects. Procedia - Social and Behavioral Sciences, 66, 432-440.

Sheeran, P. (2002). Intention-behavior relations: A conceptual and empirical review. European Review of Social Psychology, 12, 1-36.

Sternberg, R. J. (2002). The theory of successful 
intelligence and its implications for languageaptitude testing. In P. Robinson (Ed.), Individual differences and instructed language learning (pp. 13-43). Amsterdam: John Benjamins.

Subekti, A. S. (2017). The notions "integrative orientation" and "instrumental orientation" and their extents of relevance in today's ELT motivational studies: A critical analysis. ELT Perspective, 5(1), 1-11.

Taguchi, T., Magid, M., \& Papi, M. (2009). The L2 motivational self system among Japanese, Chinese, and Iranian learners of English: a comparative study. In Z. Dornyei \& E. Ushioda (Eds.), Motivation, language identity, and the L2 self (pp. 66-97). Bristol, UK: Multilingual Matters.

Thomas, G. (2013). How to do your research project: $A$ guide for students in education and applied social sciences. London: Sage Publications Ltd.

Tremblay, P. F., \& Gardner, R. C. (1995). Expanding the motivation constructs in language learning. The Modern Language Journal, 79, 505-520.

Ueki, M., \& Takeuchi, O. (2012). Validating the L2 motivational self system in a Japanese EFL context: The interplay of L2 motivation, L2 anxiety, self-efficacy, and the perceived amount of information. Language Education \& Technology, $49,1-22$.

Ushioda, E. (2006). Language motivation in a reconfigured Europe: Access, identity, autonomy. Journal of Multilingual and Multicultural Development, 27(2), 148-161. https://doi.org/10.1080/01434630608668545
Ushioda, E. (2011). Language learning motivation, self, and identity: Current theoritical perspectives. Computer Assisted Language Learning, 24(3), 199-210.

Yaghoubinejad, H., Zarrinabadi, N., \& Ketabi, S. (2016). Fluctuations in foreign language motivation: An investigation into Iranian learners' motivational change over time. Springer Science+Bussiness Media New York, June. https://doi.org/10.1007/s12144-016-9467-6

Yashima, T. (2002). Willingness to communicate in a second language: The Japanese EFL context. The Modern Language Journal, 86, 54-66.

Yashima, T. (2009). International posture and the ideal L2 self in the Japanese EFL context. In Z. Dornyei \& E. Ushioda (Eds.), Motivation, language identity, and the L2 self (pp. 144-163). Bristol, UK: Multilingual Matters.

You, C., \& Dornyei, Z. (2014). Language learning motivation in China: Results of a large-scale stratified survey. Applied Linguistics, August, 126. https://doi.org/10.1093/applin/amu046

You, C., Dornyei, Z., \& Csizer, K. (2015). Motivation, vision, and gender: A survey of learners of English in China. Language Learning, 66(1), 94-123.

Yu, B., \& Downing, K. (2012). Determinants of international students' adaptation: Examining effect of integrative motivation, instrumental motivation, and second language proficiency. Educational Studies, 38(4), 457-471. https://doi.org/10.1080/03055698.2011.643111 


\section{APPENDIX}

L2MSS questionnaire items with percentages of participants selecting each alternative

\begin{tabular}{|c|c|c|c|l|}
\hline Strongly Agree & Agree & $\begin{array}{c}\text { Neither Agree nor } \\
\text { Disagree }\end{array}$ & Disagree & Strongly Disagree \\
\hline
\end{tabular}

1. I can imagine myself living abroad and having a discussion in English.
$37.5^{*}$
51.8
10.7
0

2. I can imagine myself living abroad and using English effectively for communicating with locals.
28.6
58.9
12.5
0
0

3. I can imagine a situation where I am speaking English with foreigners.

$\begin{array}{lllll}28.6 & 62.5 & 8.9 & 0 & 0\end{array}$

4. I can imagine myself speaking English with international friends or colleagues.

$\begin{array}{lcccc}28.6 & 58.9 & 12.5 & 0 & 0\end{array}$

5. I can imagine myself speaking English as if I were a native speaker of English.

$\begin{array}{lllll}25 & 25 & 39.3 & 8.9 & 1.8\end{array}$

6. Whenever I think of my future career, I imagine myself using English.
42.9
41.1
14.3
0
1.8

7. The things I want to do in the future require me to use English.
71.4
28.6
0
0
0

8. I can imagine myself studying in a university where all of my courses are taught in English.
30.4
53.6
14.3
0
1.8

9. I can imagine myself writing English e-mail fluently.
37.5
42.9
16.1
3.6
0

Ought-to L2 Self

10. I study English because people around me think it is important.
39.3
32.1
14.3
14.3
0

11. Learning English is necessary because people around surrounding me expect me to do so.
35.7
41.1
10.7
12.5

0

12. My parents believe that I must study English to be an educated person.
41.1
39.3
$14.3 \quad 3.6$
1.8

13. I consider learning English important because people I respect think that I should do it.
32.1
41.1
12.5
14.3

14. Studying English is important to me in order to gain acknowledgment of my teachers and peers.

15. I will have a negative impact on my life if I do not learn English.
33.9
32.1
23.2

23.2

16. Studying English is important to me because an educated person is supposed to be able to speak English.

17. Studying English is important to me because other people will respect me more if I have a knowledge of English.
3.6
28.6
41.1
21.4

18. If I fail to learn English, I will be letting other people down.
17.9
7.1
16.1
46.4
12.5

L2 Learning Experience

19. I like the atmosphere of my English class.

$$
23.2 \quad 55.4
$$

20. I find learning English very interesting.

$41.1 \quad 50$
look forward to English classes.

21. I always look forward to English classes

12.5
enjoy learning English.

$25 \quad 55.4$

$55.4 \quad 17.9$

14.3

5.4

1.8

22. I really enjoy

$$
26.8 \quad 42.9 \quad 23.2
$$

24. I like my English teacher because of his/her fun English class.
19.6
50
25

7.1

1.8

0

10.7

1.8

1.8

0

25. My classmates in my English class help me understand English better.

$$
28.6 \quad 44.6 \quad 23.2
$$

1.8

1.8

26. The materials in my English class suit my needs.

$$
23.2 \quad 57.1 \quad 16.1
$$

5.4

3.6

1.8

1.8

27. The level of difficulty of English materials helps me improve my English.

$46.4 \quad 46.4 \quad 7.1 \quad 0$

* Percentages may not add to 100 due to their being rounded up to the nearest whole number. 